University of Montana

ScholarWorks at University of Montana

Numerical Terradynamic Simulation Group

Publications

Numerical Terradynamic Simulation Group

4-1993

\title{
A Physiology-Based Gap Model of Forest Dynamics
}

A. D. Friend

H. H. Schugart

Steven W. Running

University of Montana - Missoula

Follow this and additional works at: https://scholarworks.umt.edu/ntsg_pubs

Let us know how access to this document benefits you.

\section{Recommended Citation}

Friend, A. D., Schugart, H. H. and Running, S. W. (1993), A Physiology-Based Gap Model of Forest

Dynamics. Ecology, 74: 792-797. doi:10.2307/1940806

This Article is brought to you for free and open access by the Numerical Terradynamic Simulation Group at ScholarWorks at University of Montana. It has been accepted for inclusion in Numerical Terradynamic Simulation Group Publications by an authorized administrator of ScholarWorks at University of Montana. For more information, please contact scholarworks@mso.umt.edu. 


\title{
A PHYSIOLOGY-BASED GAP MODEL OF FOREST DYNAMICS ${ }^{1}$
}

\author{
A. D. FRIEND ${ }^{2}$ AND H. H. SCHUGART \\ Department of Environmental Sciences, Clark Hall, \\ University of Virginia, Charlottesville, Virginia 22903 USA \\ S. W. RUNNING \\ School of Forestry, University of Montana, Missoula, Montana 59812 USA
}

\begin{abstract}
A computer model of forest growth and ecosystem processes is presented. The model, HYBRID, is derived from a forest gap model, an ecosystem process model, and a photosynthesis model. In HYBRID individual trees fix and respire carbon, and lose water daily; carbon partitioning occurs at the end of each year. HYBRID obviates many of the limitations of both gap models and ecosystem process models. The growth equations of gap models are replaced with functionally realistic equations and processes for carbon fixation and partitioning, resulting in a dynamic model in which competition and physiology play important roles.

The model is used to predict ecosystem processes and dynamics in oak forests in Knoxville, Tennessee (USA), and pine forests in Missoula, Montana (USA) between the years 1910 and 1986. The simulated growth of individual trees and the overall ecosystemlevel processes are very similar to observations. A sensitivity analysis performed for these sites showed that predictions of net primary productivity by HYBRID are most sensitive to the ratio of $\mathrm{CO}_{2}$ partial pressure between inside the leaf and the air, relative humidity, ambient $\mathrm{CO}_{2}$ partial pressure, precipitation, air temperature, tree allometry, respiration parameters, site soil water capacity, and a carbon storage parameter.
\end{abstract}

Key words: ecosystem process model; forest; gap model; leaf area index; modelling; Pinus contorta; productivity; Quercus alba; respiration; sapwood; storage; tree.

Forest models are necessary tools if we are to assess likely impacts of global environment change on terrestrial ecosystems. Bossel (1991) advocated that the next generation of forest models should be based on the merging of tree process models ("models whose dynamics are determined mostly by the physiological processes at the tree level") and gap models ("models whose dynamics are determined mostly by interspecies (light) competition processes at the forest gap level"). This is a brief description of such a hybrid model, together with sample predictions and a sensitivity analysis.

The model, HYBRID (version 1.0), grew from an attempt to merge the gap model ZELIG (Urban 1990, Urban et al. 1991) with the ecosystem-process model FOREST-BGC (Running and Coughlan 1988). By combining these models, it was intended that predictions could be made of responses to environmental change in both biogeochemical processes and individual species distributions and dominance patterns, from a more mechanistic basis than before.

ZELIG is an example of the FORET class of gap models of forest growth, which are based on the JA-

'Manuscript received 24 December 1991; revised and accepted 17 August 1992.

${ }^{2}$ Present address: Institute of Terrestrial Ecology, Edinburgh Research Station, Bush Estate, Penicuik, Midlothian EH26 0QB, Scotland.
BOWA model of Botkin et al. (1972). These forest gap models have been reviewed by Shugart (1984). They have an annual timestep and are designed to predict the course of succession over many years. Individual trees are grown in plots and the potential growth of each tree is predicted directly from its diameter at breast height (dbh). This potential dbh increment is reduced by the extent to which the average annual light, water, temperature, and nutrient conditions experienced by each tree are sub-optimal. Each modeled plot can contain many individuals, but it is assumed that there is horizontal homogeneity in resources. These models are essentially descriptive in nature (Bossel et al. 1991). However, they have been used to accurately predict the course of succession in many different types of forest, and represent an efficient method for modeling competition for light.

By contrast, the "big-leaf" FOREST-BGC model of Running and Coughlan (1988) is used to predict stand photosynthesis, productivity, and the hydrological balance of a forest using daily climate data and a daily timestep. It treats the whole forest as one large tree, with one big leaf a hectare in size that has a thickness proportional to the leaf area index. Carbon is fixed and respired, and water is lost, daily. At the end of each simulated year the carbon accumulated by this big leaf is partitioned to the leaf, stem, and root components for growth and replacement of carbon lost by respiration and litterfall. Maintenance respiration is cal- 
TABLE 1. Species parameters used in the simulations. $A=$ photosynthesis. All parameters are derived from published sources, except leaf chlorophyll and effective root hydraulic conductivity.

\begin{tabular}{|c|c|c|c|c|}
\hline Parameter & Constants* & $\begin{array}{l}\text { Lodgepole } \\
\text { pine }\end{array}$ & White oak & Unit \\
\hline Bark thickness conversion factor & & 0.0075 & 0.033 & $\mathrm{~cm} / \mathrm{cm}$ \\
\hline Allometric wood dry mass & $a$ & 0.07194 & 0.0914 & $\mathrm{~kg}$ \\
\hline on $\mathrm{dbh}$ & $b$ & 2.449 & 2.2537 & $\mathrm{~cm}$ \\
\hline Allometric branch dry mass & $a$ & 0.00912 & 0.0274 & $\mathrm{~kg}$ \\
\hline on dbh & $b$ & 2.244 & 2.3371 & $\mathrm{~cm}$ \\
\hline Allometric dbh on stem & $a$ & 0.1605 & 0.1044 & $\mathrm{~cm}$ \\
\hline dry mass & $b$ & 0.4132 & 0.4579 & $\mathrm{~kg}$ \\
\hline Percentage of live sapwood & & 5 & 27.9 & $\%$ \\
\hline $\begin{array}{l}\text { Specific leaf area (total leaf area, } \\
\text { carbon mass only) }\end{array}$ & & 21.9 & 26.7 & $\mathrm{~m}^{2} / \mathrm{kg}$ \\
\hline Total/projected leaf area & & 2.5 & 1.0 & $\mathrm{~m}^{2} / \mathrm{m}^{2}$ \\
\hline Canopy light extinction coefficient & & -0.5 & -0.4 & (dimensionless) \\
\hline $\begin{array}{l}\text { Optimal temperature for } \\
\text { electron transport }\end{array}$ & & 21 & 31 & 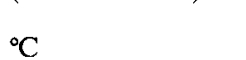 \\
\hline Effective root hydraulic conductivity & & & & \\
\hline (per unit of root dry mass) & & 0.000215 & 0.00023 & $\mathrm{~mol} \cdot \mathrm{g}^{-1} \cdot \mathrm{MPa}^{-1} \cdot \mathrm{s}^{-1}$ \\
\hline Leaf dark respiration at $25^{\circ} \mathrm{C}$ & & 1.05 & 1.75 & $\mu \mathrm{mol} \cdot \mathrm{m}^{-2} \cdot \mathrm{s}^{-1}$ \\
\hline Nitrogen in chlorophyll & & 0.6321 & 2.6743 & $\mathrm{mmol} / \mathrm{m}^{2}$ \\
\hline$A$ /light response curvature & & 0.45 & 0.45 & (dimensionless) \\
\hline$A /$ light response initial slope & & 0.28 & 0.28 & (dimensionless) \\
\hline Years leaf remains on tree & & 3 & 1 & yr \\
\hline Root to leaf dry mass ratio (as carbon) & & 4.33 & 13.64 & $\mathrm{~kg} / \mathrm{kg}$ \\
\hline Sapwood area/total leaf & & & & \\
\hline area coefficient & & 0.35 & 0.4 & $\mathrm{~m}^{2} / \mathrm{cm}^{2}$ \\
\hline b2† & & 48.63 & 43.63 & (dimensionless) \\
\hline b3t & & 0.1216 & 0.1091 & (dimensionless) \\
\hline Percentage of total root mass that is fine & & 23 & 7.3 & $\%$ \\
\hline
\end{tabular}

* The allometric constants are used in the equation: $y=a x^{b}$, where $x=\mathrm{dbh}$ or stem dry mass. Constants $a$ and $b$ are the $P$ values in Eq. 1 .

$\dagger$ Height $=137+(\mathrm{b} 2 \cdot \mathrm{dbh})-\left(\mathrm{b} 3 \cdot \mathrm{dbh}^{2}\right)$; height and dbh units are centimetres.

culated from the temperature and the amount of woody biomass; growth respiration and partitioning are calculated using simple ratios.

The aim of producing HYBRID was to obviate limitations inherent in each type of model. An important criticism of the FORET class of models is that, because trees are not grown with a mechanistic treatment of daily canopy-level photosynthesis and transpiration, these models may well be inadequate for predicting the responses of forests to climate and atmospheric $\mathrm{CO}_{2}$ change (Bossel et al. 1991). Moreover, as Bossel et al. (1991) pointed out, since gap models are essentially descriptive they cannot be used to determine why trees grow in a particular way, and how growth might have been different under other conditions. FOREST-BGC treats leaf and growth processes more mechanistically; as a result it has been successful in predicting productivity and hydrological relations under widely different climates (Running and Coughlan 1988). However, since it does not actually grow individual trees it cannot be used either to predict changes in the distribution of species, or to allow for the different physiological and morphological characteristics of different species. In addition, its photosynthesis and respiration routines are empirically based, and are not constrained with respect to one another. Perhaps most importantly, it does not allow for an internal change in leaf area index (LAI).
THE MODEL

The initial aim of HYBRID was to improve the physiological realism of tree growth in FORET-type gap models. The first step was to incorporate the FOREST-BGC code into that of ZELIG. Following this, the FOREST-BGC routines for carbon fixation, respiration, and allocation were substantially modified. Essentially, in HYBRID each individual in each plot (as modeled by ZELIG) is treated separately with respect to daily transpiration, carbon fixation, and respiration, but the light environment is treated at the plot level as in ZELIG. Daily stomatal conductance of each individual is calculated to predict fluxes of $\mathrm{CO}_{2}$ and $\mathrm{H}_{2} \mathrm{O}$ between the foliage and the atmosphere. The flux of $\mathrm{H}_{2} \mathrm{O}$ is summed across individuals in each plot for each day, and then subtracted from the soil water; the flux of $\mathrm{CO}_{2}$ is summed across days, to give annual productivity. Soil water is followed daily (as in FORESTBGC) at a plot level. Each individual is assigned a set of fundamental physiological parameters, depending on its species (e.g., Table 1). These are used at the daily and annual timesteps to calculate carbon and water dynamics for each individual. If a tree is deciduous then only maintenance respiration is calculated on nongrowing season days. Allocation of carbon within each individual occurs at an annual timestep.

Daily timestep. Daily climate drivers and plot-level 
water fluxes are calculated as in FOREST-BGC, except that average canopy light is calculated for each crown and transpiration is summed across individuals. The daily mean light level for each individual is used to drive the photosynthesis and conductance routines. The procedures used by FOREST-BGC to calculate photosynthesis and stomatal conductance have been replaced by a version of the detailed photosynthesis and conductance model PGEN (Friend 1991). By assuming optimal stomatal conductance, PGEN can calculate leaf-level photosynthesis and stomatal conductance under any environmental conditions, for any $\mathrm{C}_{3}$ species, with minimal species-specific parameterization. Optimum conductance is calculated with respect to the trade-off between leaf water potential and internal $\mathrm{CO}_{2}$ partial pressure. A direct effect of leaf water potential on photosynthesis is assumed to occur. Since leaf water potential is reduced as transpiration increases, there is an optimal stomatal conductance for any set of environmental and biological conditions (Friend 1991). In HYBRID, leaf water potential is calculated as in PGEN except that the effect of mean foliage height is also included (Friend 1992). It is assumed that there is no carbon or water exchange in the foliage if the minimum night temperature is $<0^{\circ} \mathrm{C}$.

PGEN, as adjusted for use in HYBRID, is simplified in three key ways: (1) the ratio of ambient $\mathrm{CO}_{2}$ partial pressure to that inside the leaves is fixed at 0.74 ; (2) only electron-transport-limited photosynthesis is considered (because the canopy is usually light limited, Rubisco-limited photosynthesis is not considered), and (3) leaf temperature is assumed to equal air temperature. These three simplifications were found to have a marked effect on run time, and the last two had little effect on the predictions of HYBRID at the sites simulated. However, as indicated in the sensitivity analysis below, the first simplification is crucial to estimates of productivity made by HYBRID.

Both night foliage- and 24-h wood-maintenance respiration are also calculated at the daily timestep. The former is taken from Running and Coughlan (1988). The latter is based on temperature and the live woodytissue mass of each tree, utilizing the constant measured by Ryan (1990), enabling HYBRID to calculate the maintenance respiration of any tree species. Live woody biomass is calculated from sapwood volume and the proportion of sapwood that is alive (live woody biomass is assumed to occur in all woody tissue with the same ratio to total biomass).

Annual timestep. The daily carbon balance of each individual is summed across days in each year. Litter production occurs at the end of the year, as in FOREST-BGC. The allocation routine then partitions the available carbon among the roots, stems, branches, and foliage of each tree (growth respiration is treated as in FOREST-BGC). In ZELIG, foliage biomass is an allometric function of diameter at breast height (dbh). However, there is evidence that there is a much closer relationship with sapwood area (e.g., Grier and Waring 1974). Thus, in HYBRID the amount of carbon partitioned to foliage is determined by the sapwood area, using a constant ratio for each species. It is assumed that a species-specific constant amount of root is required to support a given amount of foliage. Thus, root allocation is determined by foliage allocation. Carbon remaining after foliage and root growth is partitioned to the storage (considered to be $2 / 3$ of the live woody biomass), stem, and branch fractions. After storage has been filled, the remaining carbon is split between the stem and branches, using species-specific allometry. A new dbh is then allometrically calculated from the new stem biomass. Since the maintenance respiration of the wood is proportional to the sapwood volume, this partitioning logic alone would result in a rapid slowdown in growth. Thus it is essential that heartwood growth is predicted as it is required. This occurs whenever there is insufficient carbon available (including storage) to produce the full amount of foliage that could potentially be supported by the sapwood area, or if the lowest $1 \mathrm{~m}$ layer of foliage is a net sink for carbon. Calculating heartwood growth in this way has the important consequence that photosynthesis and respiration in each tree are closely coupled: the ratio between foliage biomass and woody respiring biomass changes only with $\mathrm{dbh}$ (for geometric reasons). The effect of this constraint is that HYBRID represents an hypothesis for the control of leaf area index, LAI, and has the potential to predict how LAI responds to environmental conditions such as precipitation and atmospheric $\mathrm{CO}_{2}$. LAI in HYBRID is constrained by the total carbon budget of each tree, which in turn is constrained by climate.

Trees in HYBRID are killed as in ZELIG (Urban 1990, based on Botkin et al. 1972), though using foliage biomass instead of diameter increment to indicate growth status. "Agemax"-related mortality, as in ZELIG, was not used in the model runs presented here. The regeneration routine used in ZELIG has been incorporated into HYBRID, but is not used here.

\section{SAMPle Predictions}

HYBRID was used to simulate ecosystem dynamics in a lodgepole pine (Pinus contorta) forest in Missoula, Montana, and a white oak (Quercus alba) forest in Knoxville, Tennessee. Parameters required by HYBRID for these two species are given in Table 1. These were derived from the literature except for leaf chlorophyll content and root hydraulic conductivity, which were altered until PGEN (Friend 1991) gave the same values of photosynthesis and stomatal conductance as did measurements. A monospecific, mixed-age stand was simulated at each site, with oak or pine in Knoxville, and pine in Missoula. Twenty $200-\mathrm{m}^{2}$ plots were simulated at each site, with 220 different-sized oaks spread over the Knoxville plots, and 310 differentsized pines spread over the Missoula and Knoxville 
KNOXVILLE
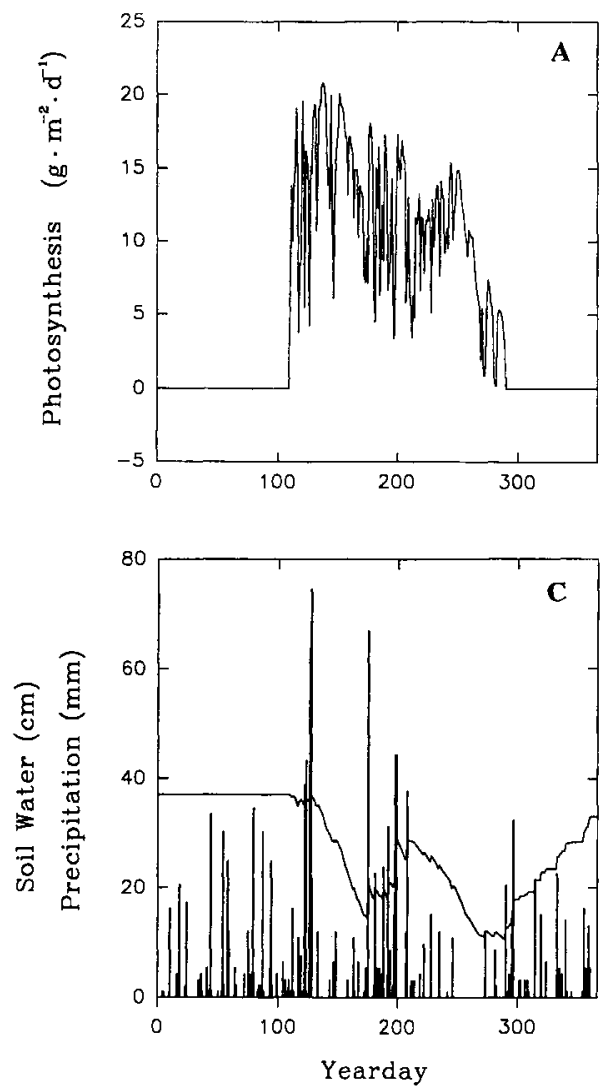

MISSOULA
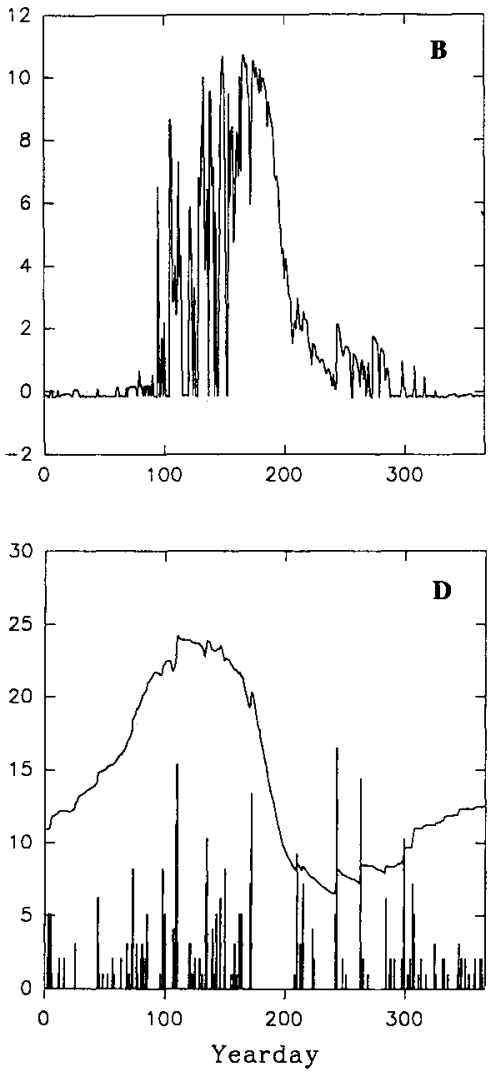

Fig. 1. Predicted daily canopy photosynthesis, measured as carbon flux, and soil water levels (with precipitation, bars) in Knoxville, Tennessee and Missoula, Montana for the year 1984.

plots. Daily climate for the two sites was obtained from site measurements (EarthInfo, Inc., Boulder, Colorado, USA), and radiation was simulated as in Running and Coughlan (1988). The growing season in Knoxville was assumed to start on yearday (day of year) 110 and finish on yearday 289 . Simulations were conducted for the period 1910 through 1986. Ambient $\mathrm{CO}_{2}$ was increased during this period according to Schneider (1989).

Some of the within-year results from this simulation for 1984 (a typical year) are given in Fig. 1. Daily photosynthesis is largely controlled by phenology (in Knoxville), soil water, and temperature. Key differences are apparent between the two sites. The longterm results of this simulation are given in Fig. 2. These predictions compare favorably with observations and other estimates (e.g., Knoxville: Harris et al. 1975; Missoula: Pearson et al. 1984). The year-to-year variation in net primary productivity (NPP) and streamflow can be explained by the climatic variation in precipitation and temperature. Streamflow is reduced by increasing LAI at both sites. These results indicate that species matter in determining large-scale ecosystem attributes such as NPP, but may result in similar values of LAI in the same climate.

\section{A Sensitivity Analysis}

We tested the sensitivity of average NPP predicted by HYBRID over the last $5 \mathrm{yr}$ of the simulations to variation in all major parameters. Each parameter $P$ was individually increased $\left(P_{1}\right)$ and decreased $\left(P_{0}\right)$ by $10 \%$. An index of sensitivity was then calculated. This index $(\beta)$ is defined as:

$$
\beta=\frac{\mathrm{NPP}_{1}-\mathrm{NPP}_{0}}{\mathrm{NPP}_{0}} / \frac{P_{1}-P_{0}}{P_{0}},
$$

where $\quad \mathrm{NPP}_{0}=\mathrm{NPP}$ when parameter is $P_{0}$, and $\quad \mathrm{NPP}_{1}=\mathrm{NPP}$ when parameter is $P_{1}$.

The $\beta$ values derived from this analysis are plotted in Fig. 3. It is clear that there is a large number of biological parameters to which predicted NPP in these two species at these two sites is relatively insensitive. The exceptions to this are the $p_{i} / p_{a}$ ratio and various parameters used in allometric calculations. Increasing $p_{i} / p_{a}$ has a large negative effect on predicted NPP at both sites. This is due to a reduction in $\mathrm{CO}_{2}$ uptake relative to $\mathrm{H}_{2} \mathrm{O}$ loss on a leaf area basis (i.e., a reduction in water use efficiency), despite absolute $\mathrm{CO}_{2}$ uptake 

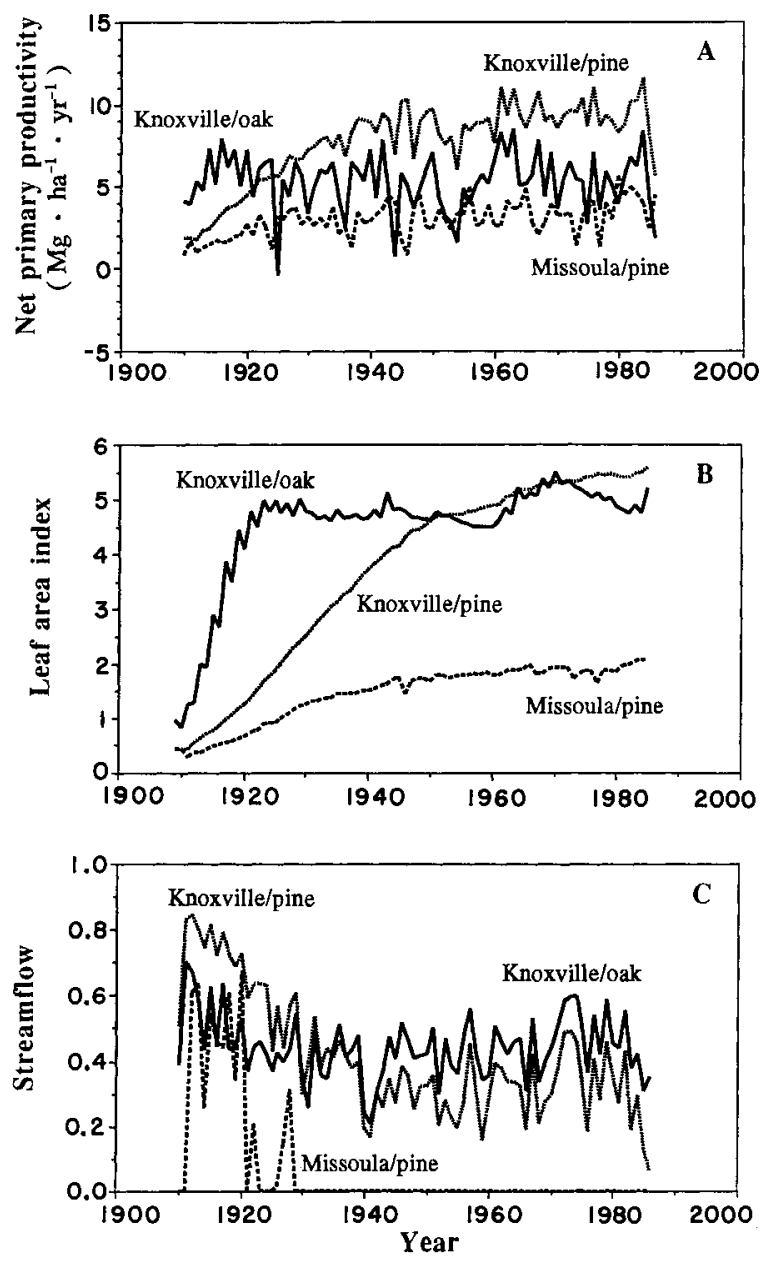

FIG. 2. Predicted changes in net primary productivity (A), projected leaf area index (B), and proportion of precipitation in streamflow (C) in a Knoxville white oak stand, a Knoxville lodgepole pine stand, and a Missoula lodgepole pine stand.

marginally increasing. $p_{i} / p_{a}$ is a critical parameter because it determines the relationships among ambient $\mathrm{CO}_{2}, \mathrm{CO}_{2}$ fixation, and $\mathrm{H}_{2} \mathrm{O}$ loss. This relationship is amplified in a model such as HYBRID because of feedbacks through soil water. The long-term average ratio predicted by the full PGEN model for the same conditions is, in fact, close to that assumed in HYBRID. This indicates that the time interval over which stomatal conductance is optimized is crucial. The other important biological parameters are those used to calculate biomass values allometrically from $\mathrm{dbh}$, and vice versa: $W(b)=$ exponent for stem wood dry mass from $\mathrm{dbh} ; B(b)=$ exponent for branch dry mass from $\mathrm{dbh} ;$ and $D(a)=$ multiplier for dbh from stem dry mass. The importance of these allometric values is partly due to their use in exponential functions, but also to their role in determining the mass of living tissue that is responsible for maintenance respiration. Of the remaining biological parameters, NPP is most affected by the growth and maintenance respiration constants, though the latter is important only in white oak (presumably because of the large amount of living biomass).

There are four other biological parameters of notable importance in determining predicted NPP at these two sites in HYBRID. These are the percentage of living woody biomass used for storage (\%store), the efficiency of converting photons into excited electrons for use in photosynthesis, the percentage of sapwood that is alive, and the optimum temperature for photosynthetic electron transport. Also of importance is soil water capacity (SWC).

With regard to the daily environmental parameters, increasing relative humidity, atmospheric $\mathrm{CO}_{2}$, or precipitation has a large beneficial effect at both sites; increasing temperature has a large negative effect. The latter is largely due to increased respiration (the optimal temperature for photosynthesis is pre-adapted to site conditions). Predicted NPP is not very sensitive to radiation at these two sites.

It should be emphasized that the relative importance of the different parameters derived from this sensitivity analysis will not be true of all sites, or of all species, and also that the sensitivity of other ecosystem attributes is unlikely to give the same ranking of parameters as for NPP.

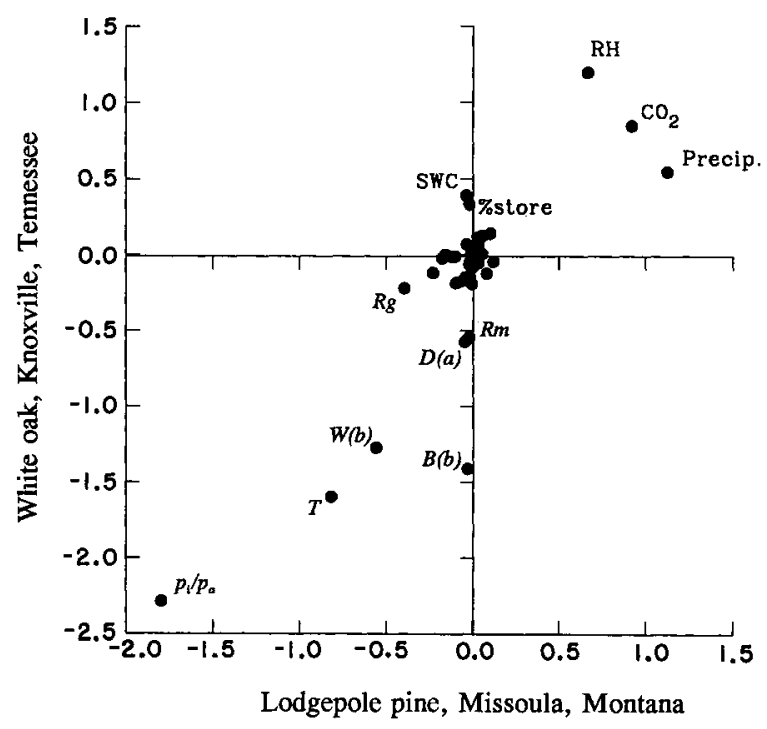

FIG. 3. Sensitivity analysis results. The parameters to which net primary productivity (NPP) is most sensitive are farthest from the zero-zero point. $B(b)=$ exponent for calculating stem wood dry mass from diameter at breast height (dbh); $\mathrm{CO}_{2}=$ air $\mathrm{CO}_{2}$ partial pressure; $D(a)=$ multiplier for calculating $\mathrm{dbh}$ from stem diameter; \%store = percentage of living sapwood used for storage; $p_{i} / p_{a}=$ ratio of $\mathrm{CO}_{2}$ partial pressure between inside leaf and air; Precip. = precipitation; $R g=$ growth respiration coefficient; $\mathbf{R H}=$ relative humidity; $R m=$ maintenance respiration coefficient; SWC $=$ soil water-holding capacity; $T=$ temperature, $W(b)=$ exponent for calculating stem wood dry mass from dbh. Methods are described in $A$ sensitivity analysis. 


\section{CONCLUSIONS}

HYBRID is a new type of general forest ecosystem model that simultaneously treats tree demography, competition, physiology, and larger-scale physical processes mechanistically. It can be viewed as an algorithm designed to predict the most advantageous sapwood area in each individual tree at a particular site from year to year. Trade-offs at the stomatal and whole-tree carbon balance level control both the long- and shortterm dynamics of HYBRID, resulting in realistic predictions at both scales. This results in new insights that were not possible from its predecessors.

\section{ACKNOWLEDGMENTS}

This research was funded by the University of Virginia Global Systems Analysis Program, the NSF (grants BSR8807882 to the University of Virginia and BSR-8919646 to the University of Montana), and the EPA (grants CR-817542 to the University of Virginia and CR-817633-01-0 to the University of Montana). We wish to thank Ray Hunt, Erica Schwarz, Tom Smith, Dean Urban, Ian Woodward, and Alan Yeakley for their suggestions, help, and criticism of HYBRID and this manuscript, and Lyndele von Schill for providing logistical support throughout this project.

\section{Literature Cited}

Bossel, H. 1991. Modelling forest dynamics: moving from description to explanation. Forest Ecology and Management 42:129-142.

Bossel, H., H. Krieger, H. Schäfer, and N. Trost. 1991. Simulation of forest stand dynamics, using real-structure process models. Forest Ecology and Management 42:3-21.

Botkin, D. B., J. F. Janak, and J. R. Wallis. 1972. Some ecological consequences of a computer model of forest growth. Journal of Ecology 60:849-872.
Friend, A. D. 1991. Use of a model of photosynthesis and leaf microenvironment to predict optimal stomatal conductance and leaf nitrogen partitioning. Plant, Cell and Environment 14:895-905.

1992. The prediction and physiological significance of tree height. In H. H. Shugart and A. M. Solomon, editors. Vegetation dynamics modeling and global change. Chapman and Hall, London, England, in press.

Grier, C. C., and R. H. Waring. 1974. Conifer foliage mass related to sapwood area. Forest Science 20:205-206.

Harris, W. F., P. Sollins, N. T. Edwards, B. E. Dinger, and H. H. Shugart. 1975. Analysis of carbon flow and productivity in a temperate deciduous forest ecosystem. Pages 116-122 in D. E. Reichle, J. F. Franklin, and D. W. Goodall, editors. Productivity of world ecosystems. National Academy of Sciences, Washington, D.C., USA.

Pearson, J. A., T. J. Fahey, and D. H. Knight. 1984. Biomass and leaf area in contrasting lodgepole pine forests. Canadian Journal of Forest Research 14:259-265.

Running, S. W., and J. C. Coughlan. 1988. A general model of forest ecosystem processes for regional applications. I. Hydrological balance, canopy gas exchange and primary production processes. Ecological Modelling 42:125-154.

Ryan, M. G. 1990. Growth and maintenance respiration in stems of Pinus contorta and Picea engelmannii. Canadian Journal of Forest Research 20:48-57.

Schneider, S. H. 1989. The changing climate. Scientific American 261(September):70-79.

Shugart, H. H. 1984. A theory of forest dynamics: the ecological implications of forest succession models. SpringerVerlag, New York, New York, USA.

Urban, D. L. 1990. A versatile model to simulate forest pattern. A user's guide to ZELIG version 1.0. University of Virginia, Charlottesville, Virginia, USA.

Urban, D. L., G. B. Bonan, T. M. Smith, and H. H. Shugart. 1991. Spatial applications of gap models. Forest Ecology and Management 42:95-110. 